Dunamis: Jurnal Teologi dan Pendidikan Kristiani

Volume 6, Nomor 1 (Oktober 2021)

ISSN 2541-3937 (print), 2541-3945 (online)

https://www.sttintheos.ac.id/e-journal/index.php/dunamis

DOI: $10.30648 /$ dun.v6i1.633

Submitted: 19 Juli 2021

Accepted: 27 Oktober 2021

Published: 31 Oktober 2021

\title{
Partisipasi Sosial-Politik sebagai Praktik Hospitalitas Kaum Pentakostal
}

\author{
Fransiskus Irwan Widjaja ${ }^{1}$; Harls Evan R. Siahaan ${ }^{2 *}$; Octavianus Nathanael ${ }^{3}$ \\ Sekolah Tinggi Teologi REAL, Batam ${ }^{1}$; Sekolah Tinggi Teologi Pelita Bangsa Jakarta ${ }^{2}$; \\ Sekolah Tinggi Teologi Misi William Carey, Medan ${ }^{3}$ \\ evandavidsiahaan@gmail.com*
}

\begin{abstract}
The involvement of the church in social life outside the church is something that continues to struggle from time to time; the church, on the one hand, felt compelled to be involved in all aspects of life; on the other, it felt sufficient to focus on the spiritual dimension of life. Meanwhile, participation in the social domain is often articulated with religious mission activities that wish to win souls and increase the number of church members. This article aimed to present a theological reflection framework on hospitality in a Pentecostal perspective, as a spirituality that drives the participatory philosophy of Pentecostals in the public sphere, both socially and politically. The method used is descriptive analysis, with a literature study approach. The result is that the hospitality attitude of the early church in the Acts constructs a Pentecostal reflection of the participation of Pentecostals in the public sphere.
\end{abstract}

Keywords: hospitality; social care; The Acts; the Pentecostals; church participation; Pentecostalism; Pentecostal theology

\begin{abstract}
Abstrak
Keterlibatan gereja dalam kehidupan sosial di luar gereja merupakan hal yang terus mengalami pergumulan dari waktu ke waktu; gereja di satu sisi merasa harus terlibat dalam seluruh aspek kehidupan, di sisi lain merasa cukup untuk memfokuskan pada dimensi kehidupan rohani. Sementara itu, partisipasi pada domain sosial tidak jarang diartikulasikan dengan kegiatan misi gerejawi yang ingin memenangkan jiwa dan menambahkan jumlah anggota gereja. Artikel ini bertujuan menyajikan sebuah kerangka refleksi teologis tentang hospitalitas dalam perspektif Pentakostal, sebagai spirtualitas yang menggerakkan sikap partisipatif kaum Pentakostal pada ruang publik, baik secara sosial dan politik. Metode yang digunakan adalah analisis deskriptif, dengan pendekatan studi literatur. Hasilnya, sikap hospitalitas jemaat mula-mula pada narasi Kisah Para Rasul mengonstruksi sebuah perenungan Pentakostal mengenai partisipasi kaum Pentakostal pada ruang publik.
\end{abstract}

Kata Kunci: hospitalitas; kepedulian sosial; Kisah Para Rasul; kaum Pentakostal; partisipasi gereja; Pentakostalisme; teologi Pentakosta 


\section{PENDAHULUAN}

Tema tentang kepedulian atau partisipasi sosial dan politik dalam diskusi teologi bukanlah hal yang sama sekali baru. Ernst Kantorowics pernah membahas tentang keberadaan gereja yang sekaligus menjadi alat politik di abad pertengahan ${ }^{1}$, selain konsep teologi politik yang diusung oleh Carl Schmitt ${ }^{2}$, atau Saul Newman ${ }^{3}$ yang membuat sebuah pengantar kritis terhadap teologi politik. Perhatian mereka tidak lepas dari berbagai tendensi hingga stigma yang muncul akibat gereja yang berpolitik, dari abad pertengahan hingga zaman posmodern sekarang ini. Setidaknya, peristiwa perang salib menjadi sebuah fakta ironis dari dampak "perkawinan" gereja dan politik yang pernah terjadi. Tidak hanya itu, meningkatnya ketegangan sosial pun terjadi sebagai dampak maraknya politik identitas ${ }^{4}$, yang secara tidak langsung memberikan stigma pada identitas keagamaan. Agama dan kekerasan seolah menjadi dua hal yang saling berdampingan, dan tidak jarang menjadi kendaraan politik kelompok dan golongan tertentu.

Isu agama dan politik bukanlah persoalan yang sederhana, atau dapat diseder-

${ }^{1}$ Ernst H. Kantorowicz, The King's Two Bodies: A Study in Mediaeval Political Theology. (New Jersey: Princeton University Press, 1957).

${ }^{2}$ Carl Schmitt, Political Theology: Four Chapters on the Concept of Sovereignty (Chicago: University of Chicago Press, n.d.).

${ }^{3}$ Saul Newman, Political Theology: A Critical Introduction (Cambridge: Polity Press, 2019). hanakan dengan hanya membuat tembok pemisah di antaranya. Atau, membiarkannya seperti itu, tetap pada jalinan relasional yang overlap, karena keduanya sama-sama memberikan keuntungan; agama dapat menjadi kendaraan politik, dan politik dapat memberikan ruang hegemoni atau ekspansi agama. Pada posisi inilah agama seharusnya dapat hadir sebagai katalisator, atau dinamisator kehidupan yang lebih humanis. Agama tetap berelasi dengan politik, namun bukan untuk sekadar berpolitik, melainkan mampu menciptakan kehidupan yang mengusung tinggi nilai-nilainya. Pada ruang inilah gereja dapat mengambil peran atau partisipasinya; menjadi dinamisator kehidupan politik, mengedukasi umat untuk dapat terlibat dalam praktik politik yang lebih bermartabat.

Keterlibatan gereja dalam ruang publik telah menjadi diskursus teologi lintas zaman, bahkan telah dimulai sejak zaman Yesus, ketika Ia menegaskan identitas "garam dan terang" dunia kepada para murid (Mat. 5:13-16). Bahkan, pesan Yesus yang sering dilabel dengan istilah "Amanat Agung" (Mat. 28:19-20) tidak dapat dilepaskan dari kerangka keterlibatan orang

4 Mifdal Zusron Alfaqi, "Memahami Indonesia Melalui Prespektif Nasionalisme, Politik Identitas, Serta Solidaritas," Jurnal Pendidikan Pancasila dan Kewarganegaraan 28, no. 2 (2015); Juhana Nasrudin and Ahmad Ali Nurdin, "Politik Identitas Dan Representasi Politik (Studi Kasus Pada Pilkada DKI Periode 2018-2022)," Hanifiya: Jurnal Studi Agama-Agama 1, no. 1 (2019): 34-47. 
Kristen dalam dunia sosial. Keterlibatan itu sudah terjadi sejak masa gereja ada, yang kemudian menyebar ke seluruh dunia, hingga terus mengalami multiplikasi. Namun, keterlibatan sosial itu pun tidak dapat seutuhnya dilepaskan dari kerangka misi amanat agung, sehingga terjadi semacam polarisasi, bahwa keterlibatan sosial berkelindan dengan misi-misi gerejawi. ${ }^{5}$ Lebih lanjut lagi, beberapa upaya teologisasi dilakukan untuk merefleksikan keterlibatan sosial sebagai bentuk pemberitaan Injil, yang di kemudian hari dikenal dengan istilah Social Gospel. ${ }^{6}$ Lepas dari sikap pro dan kontra terhadap Social Gospel, setidaknya teologi telah berupaya untuk mengekspresikan keterlibatan sosial gereja dalam bentuk literasi.

Artikel ini tidak dalam posisi menanggapi Social Gospel, melainkan menawarkan sebuah refleksi teologis terkait partisipasi gereja pada ruang publik, baik secara sosial dan politik, dalam perspektif Pentakostal. Hal ini mempertimbangkan adanya potensi yang besar dari kelompok Pentakostal, bahkan Karismatik. Potensi tersebut, di satu sisi, memang tidak bisa dipungkiri, bahwa pertumbuhan kuantitatif gereja-

\footnotetext{
${ }^{5}$ Bdk. Roger Haight, "The Mission of the Church in the Theology of the Social Gospel," Theological Studies 49, no. 3 (1988): 477-497.

${ }^{6}$ Beberapa tema tentang Social Gospel dapat dilihat dalam: Walter Rauschenbusch, A Theology for the Social Gospel (Michigan: IVP Books, 2008)., Ronald Cedric White, Charles Howard Hopkins, and John Coleman Bennett, The Social Gospel: Religion and Reform in Changing America (Temple
}

gereja dalam lingkup Pentakostal-Karismatik merupakan yang paling dinamis di antara kelompok Kristen lainnya, terlepas dari segala kontroversi yang diakibatkan. Hal ini pun diakui oleh Jan S. Aritonang, yang menyebutkan bahwa gereja-gereja Pentakostal di Indonesia, sejak masuknya di awal 1920, mengalami perkembangan yang luar biasa, dan makin berkembang dengan munculnya gerakan Kharismatik di tahun 1960-an. ${ }^{7}$ Selain Aritonang, pendapat Alister McGrath merujuk data tahun 2002 yang menyebutkan sekitar 500 juta orang Pentakosta di seluruh dunia. ${ }^{8}$ Fakta ini harus dilihat secara positif, lepas dari segala stigma yang tidak jarang membingkainya. Alasannya, ini adalah sebuah potensi yang perlu dioptimalkan dalam kerangka hidup bersama secara ekumenis dan nasionalis, khususnya di Indonesia. Kurangnya partisipasi sosial politik kaum Pentakostal selama ini dianggap sebagai indikasi kuatnya orientasi teologi Pentakostal dan Karismatik yang lebih banyak berkutat pada persoalan internal gereja atau denominasi alirannya.

Minggus Pranoto melakukan kritik yang menampilkan stigma "sisi gelap kepemimpinan Pentakostal-Karismatik.” De-

University Press, 1976)., Ralph E Luker, The Social Gospel in Black and White: American Racial Reform, 1885-1912 (Univ of North Carolina Press, 1998).

${ }^{7}$ Jan S. Aritonang, "Sejarah Pertumbuhan Gerakan Pentakostal Di Indonesia," Gema Teologi 35, no. 1/2 (2011).

${ }^{8}$ Alister E. McGrath, The Future of Christianity (Massachusetts: Blackwell Publisher, 2002), 108. 
ngan menunjukkan beberapa kasus individual sebagai indikatornya. ${ }^{9}$ Sekalipun, disayangkan, kritik melalui artikel jurnal ilmiah tersebut kental dengan narasi populer membalut opini yang menggenaralisir stigma “sisi gelap Pentakostal," ekspresi kekecewaan tersebut mewakili dari banyaknya kritik terhadap perilaku yang kerap dilakukan oleh orang-orang dalam kelompok Pentakostal-Karismatik. Lepas dari perlunya pembuktian terhadap beberapa kritik, semua hal tersebut seyogyanya menjadi refleksi dan titik awal untuk merekonstruksi dimensi pelayanan yang kurang disentuh selama ini oleh kelompok Pentakostal. Kelompok Pentakostal harus berani terbuka dan membenahi diri, tanpa harus merasa terluka dan terkucilkan, agar dapat mengembangkan ruang aktualisasi yang lebih luas bagi pencapaian keutuhan gereja.

Beberapa kajian terdahulu menunjukkan pembahasan Pentakostalisme terkait aksi sosial, seperti yang dilakukan oleh Elia

\footnotetext{
${ }^{9}$ Minggus M Pranoto, "Sisi Gelap Kepemimpinan Pentakostal-Karismatik," GEMA TEOLOGIKA: Jurnal Teologi Kontekstual dan Filsafat Keilahian 5 , no. 2 (2020): 175-186.

10 Elia Tambunan, "Pentakostalisme Dan Teori Sosial Kontemporer," Jurnal Teologi Amreta 2, no. 1 (2018).

11 Yushak Soesilo, "Pentakostalisme Dan Aksi Sosial: Analisis Struktural Kisah Para Rasul 2: 4147," DUNAMIS: Jurnal Teologi dan Pendidikan Kristiani 2, no. 2 (2018): 136-151, http://sttintheos. ac.id/e-journal/index.php/dunamis/article/view/172/ 134.

12 Sonny Eli Zaluchu, "Eksegesis Kisah Para Rasul 2:42-47 Untuk Merumuskan Ciri Kehidupan Rohani Jemaat Mula-Mula Di Yerusalem," EPIGRAPHE: Jurnal Teologi dan Pelayanan Kristiani 2, no. 2 (2019): 72-82. Bdk. Harls Evan Siahaan,
}

Tambunan, yang mengaitkan Pentakostalisme dengan teori-teori sosial kontemporer. ${ }^{10}$ Yushak Soesilo mengusulkan aksi sosial sebagai identitas Pentakostalisme berdasarkan kajian teks Kisah Para Rasul 2:41-4711; hal senada disebut Sonny Zaluchu sebagai salah satu ciri kehidupan rohani jemaat mula-mula. ${ }^{12}$ Artinya, secara mendasar, sikap peduli secara sosial telah menjadi ciri khas jemaat yang terbentuk pascapentakosta di Yerusalem; sejatinya, hal serupa menjadi karakteristik hidup kaum Pentakostal yang mengambil locus teologi pada teks-teks Kisah Para Rasul. Wolfgang Vondey pun menyebutkan bahwa formasi Pentakostal dibentuk oleh aktivitas sosial. ${ }^{13}$ Sementara itu, terkait dengan tema partisipasi politik, beberapa kajian telah dilakukan, seperti oleh Rowan Ireland dengan konteks Brazil $^{14}$, Ruth Marshall dengan konteks Nigeria $^{15}$, Edward L. Cleary dalam konteks Amerika Latin ${ }^{16}$, bahkan Amos Yong ${ }^{17}$.

\footnotetext{
"Karakteristik Pentakostalisme Menurut Kisah Para Rasul," Dunamis: Jurnal Teologi dan Pendidikan Kristiani 2, no. 1 (2017): 12-28.

13 Wolfgang Vondey, "The Impact of Culture and Social Justice on Christian Formation in Pentecostalism," Journal of Pentecostal Theology 24, no. 2 (2015): 201-216.

${ }^{14}$ Rowan Ireland, "Pentecostalism, Conversions, and Politics in Brazil," Religion 25, no. 2 (1995): 135145.

${ }^{15}$ Ruth Marshall, Political Spiritualities: The Pentecostal Revolution in Nigeria (University of Chicago Press, 2009).

${ }^{16}$ Edward L Cleary, Power, Politics, and Pentecostals in Latin America (Routledge, 2018).

${ }^{17}$ Amos Yong, In the Days of Caesar: Pentecostalism and Political Theology (Michigan: Eerdmans, 2010), 105
} 
Apa yang dilakukan dalam artikel ini bukan sekadar memadukan dua domain, sosial dan politik, terkait isu-isu Pentakostalisme, melainkan merefleksikan kedua domain partisipasi publik itu sebagai locus hospitalitas kaum Pentakostal.

Johannis Siahaya dan Harls Evan Siahaan mengajukan ide hospitalitas menurut konteks jemaat mula-mula sebagai refleksi dan sekaligus perspektif teologis kaum Pentakostal. ${ }^{18}$ Apa yang dilakukan Siahaya adalah untuk menstimulasi rasa kemanusiaan dan sepenanggungan dalam menghadapi berbagai dampak serta risiko akibat Pandemi Covid-19. Artikel ini boleh disebut sebagai kajian lanjutan dari apa yang telah dilakukan oleh Siahaya dan Siahaan sebelumnya, terkait tema hospitalitas dalam perspektif Pentakostal. Teologisasi terkait sikap hospitalitas dalam perspektif Pentakostal menjadi hal yang diperlukan untuk menstimulasi sense of humanity orang Kristen, agar tidak hanya sekadar berkutat dalam kegiatan internal gereja atau denominasinya saja, melainkan membuka ruang partisipasi secara luas ke luar gereja. Jika Siahaya dan Siahaan mencoba meng-

18 Johannis Siahaya and Harls Evan R Siahaan, "Menggagas Hospitalitas Pentakostal: Membaca Ulang Kisah Para Rasul 2: 44-47 Di Masa Pandemi," DUNAMIS: Jurnal Teologi dan Pendidikan Kristiani 5, no. 2 (2021): 426-439.

${ }^{19}$ Ibid.

20 Amos Yong, Hospitality and The Other: Pentecost, Christian Practices, and the Neighbor gagas konsepsi awal tentang Teologi Hospitalitas dalam perspektif Pentakostal terkait sikap kemanusiaan di tengah pandemi, maka kajian ini mengembangkan gagasan tersebut dalam menstimulasi dan membangkitkan sikap kepedulian atau partisipasi kaum Pentakostal pada ruang publik. Penelitian ini bertujuan untuk membingkai kerangka berpikir teologis kaum Pentakostal agar dapat berpartisipasi pada ruang publik, baik secara sosial dan politik, sebagai praktik hospitalitas.

\section{METODE PENELITIAN}

Artikel ini adalah sebuah kajian kualitatif berbasis studi literatur, yang menggunakan metode analisis deskriptif dan argumentatif. Praktik hospitalitas dalam artikel ini menggunakan konsepsi Teologi Hospitalitas yang dibagikan oleh Siahaya dan Siahaan ${ }^{19}$, dan yang tentunya juga telah mengembangkan tema hospitalitas dari Amos Yong $^{20}$ dan Amy Oden ${ }^{21}$, berdasarkan studi terhadap jemaat mula-mula. Beberapa buku dan artikel jurnal dengan tema terkait digunakan untuk memberikan pemahaman deskriptif tentang hospitalitas, selain juga menganalisis dan menyusun argumentasi me-

(New York: Orbis Books, 2008); Amos Yong, "The Spirit of Hospitality: Pentecostal Perspectives toward a Performative Theology of Interreligious Encounter," Missiology: An International Review 35, no. 1 (2007): 55-73.

21 Amy G Oden, And You Welcomed Me: A Sourcebook on Hospitality in Early Christianity (Nashville: Abingdon Press, 2001). 
lalui diskusi, untuk memperoleh kesimpulan terkait partisipasi kaum Pentakostal pada ruang publik, khususnya pada domain sosial dan politik. Beberapa teks Alkitab, khususnya dalam Kisah Para Rasul, digunakan sebatas rujukan seperti yang telah dilakukan pada kajian-kajian sebelumnya, tanpa perlu diinterpretasi ulang demi memperoleh pemahaman yang lain (baru).

\section{HASIL DAN PEMBAHASAN}

\section{Teologi Hospitalitas dalam Perspektif}

\section{Pentakostal: Sebuah Dimensi Praksis}

Istilah hospitalitas memang tidak muncul dalam Alkitab secara literal, kecuali merujuk versi yang berbahasa Inggris, seperti dalam Roma 12:13 dalam versi KJV atau ASV, yang menggunakan istilah hospitality; LAI menggunakan istilah "memberikan tumpangan." Istilah telah menjadi diskursus teologi sejak awal abad XX, dan telah mengalami perkembangan pembahasan yang sangat beragam. Namun demikian, senantiasa ada ruang, sesempit apa pun itu, untuk mengembangkannya dalam isu kehidupan bergereja atau beragama di masa sekarang. Hal ini juga yang diungkapkan oleh Veli Matti Karkainen, bahwa tema hospital-

22 Veli-Matti Karkkainen, A Constructive Christian Theology for The Pluralistic World (Michigan: William B. Eerdmans Publishing Company, 2017). 23 Joas Adiprasetya, "Hospitalitas: Wajah Sosial Gereja Masa Kini," Situs Komunitas Jemaat GKI Pondok Indah, last modified 2013, accessed November 12, 2020, https://gkipi.org/hospitalitas- litas atau memperlakukan orang lain, hingga memberikan tumpangan (Luk. 10:25-37) menjadi isu pokok dalam kehidupan di tengah keberagaman. ${ }^{22}$ Tema ini bukanlah satu-satunya yang dapat memberikan semacam solusi dalam isu keberagaman yang tidak jarang diwarnai konflik, namun hal ini dapat dipertimbangkan sebagai sebuah strategi atau sikap dalam memulai hidup bersama di tengah pluralitas.

Istilah hospitalitas, menurut Joas Adiprasetya, berarti "mengasihi orang asing sebagai sahabat," atau "menyahabati orang asing." 23 Arthur Shuterland mendefinisikan hospitalitas Kristen, “...is the intentional, responsible, and caring at welcoming or visiting, in either public or private places, those who are strangers, enemies, or distressed, without regard for reciprocation." 24 Shuterland menekankan hospitalitas Kristen pada tindakan menyambut (welcoming) atau mengunjungi (visiting) orang asing tanpa mengharapkan adanya timbal balik. Bagi Derrida, menurut Andrew Shepherd, "ethics is hospitality and hospitality is ethics. ${ }^{25}$ Sementara Christine D. Pohl mengatakan, "hospitality is not optio-

wajah-sosial-gereja-masa-kini/. diakses 12 November 2020.

${ }^{24}$ Arthur Sutherland, I Was a Stranger: A Christian Theology of Hospitality (Nashville: Abingdon Press, 2010), 6.

${ }^{25}$ Andrew Shepherd, The Gift of the Other: Levinas, Derrida, and a Theology of Hospitality (Cambridge: James Clarke \& Co., 2014), 53. 
nal for Christians, nor is it limited to those specially gifted for it. It is, instead, a necessary practice in the community of faith. "26 Pohl menandaskan hospitalitas bukan sebuah opsi atau semacam karunia yang hanya dimiliki oleh orang-orang tertentu, melainkan sebuah praktik dari komunitas iman. Letty Russell, teolog yang juga mantan anggota Faith and Order Commission dari World Council of Churches (WCC), mendefinisikan hospitalitas, “...is the practice of God's welcome by reaching across difference to participate in God's actions to bring justice and healing in our society. "27 Prinsipnya, hospitalitas tidak semata-mata bagaimana melakukan kebaikan, namun memberikan artikulasi pada sosok "yang asing" sebagai objek, sekaligus subjek, dalam sikap etis atau kebaikan.

Siahaya dan Siahaan menggunakan Kisah Para Rasul 2:44-47 untuk merefleksikan teologi hospitalitas dalam perspektif Pentakostal. ${ }^{28}$ Alasannya, pertama, kaum Pentakostal menggunakan teks-teks Kisah Para Rasul sebagai locus berteologi ${ }^{29}$; selain yang kedua, jemaat mula-mula melaku-

26 Chistine D Pohl, Making Room: Recovering Hospitality as a Christian Tradition (Grand Rapids: Wm. B. Eerdmans Publishing, 1999), 1-17.

${ }^{27}$ Letty M. Russel, Just Hospitality: God's Welcome in a World of Difference (Louisville: Westminster John Knox Press, 2009), 19.

28 Siahaya and Siahaan, "Menggagas Hospitalitas Pentakostal: Membaca Ulang Kisah Para Rasul 2: 44-47 Di Masa Pandemi."

${ }^{29}$ Robert P. Menzies, Teologi Pentakosta (Malang: Gandum Mas, 2015), 19-20. kan hospitalitas. Yong menyebut bahwa jemaat mula-mula melakukan hospitalitas ketika membuka ruang kebersamaan bagi “orang lain” yang bergabung dalam bilangan mereka setelah menjadi percaya atas pemberitaan Petrus; sikap hospitalitas ini dikerjakan oleh Roh Kudus. ${ }^{30}$ Yong menerapkan hospitalitas dalam perspektif Pentakostal ini untuk membangun dialog antariman di tengah maraknya praktik kekerasan yang mengatasnamakan agama di Sri Lanka dan Nigeria. ${ }^{31}$ Bilangan 120 orang yang mengalami peristiwa pencurahan Roh Kudus pada Kisah Para Rasul 2:1-13, telah berkembang menjadi 3000 orang (Kis. 2:41) ketika banyak dari Yahudi Diaspora, dengan beragam identitas daerah asal mereka masing-masing, menjadi percaya oleh khotbah Petrus. Jemaat mula-mula tidak menjadi eksklusif dengan komunitas yang berjumlah 120 orang itu, namun mereka membuka diri bagi setiap orang dengan identitas berbeda bergabung dalam bilangan mereka.

Jemaat mula-mula yang melakukan tindakan generous kepada anggota yang lain (Kis. 2:44-45) tidak harus dimaknai se-

30 Yong, "The Spirit of Hospitality: Pentecostal Perspectives toward a Performative Theology of Interreligious Encounter."

31 Yong, Hospitality and The Other: Pentecost, Christian Practices, and the Neighbor. Bdk. Kristin Beise Kiblinger, "Hospitality and the Other: Pentecost, Christian Practices, and the Neighbor," Buddhist-Christian Studies 29, no. 1 (2009): 156159. 
bagai sikap dan perilaku kebaikan antarorang percaya, tanpa memberi ruang perbedaan yang hakiki pada setiap anggota. Pada saat disebutkan ada hampir 3000 orang yang bertobat, dan menjadi satu entitas dengan yang 120 orang, maka sejatinya 120 orang tersebut merupakan host yang menyambut (welcoming) kehadiran "orang asing." Identitas asing tidak hanya dimaknai dalam keberagaman agama, sehingga memicu lahirnya dialog antaragama, di mana berbagai agama yang berbeda mencoba membuka ruang persahabatan bagi sesama yang asing. Namun, perbedaan selalu ada dalam satu komunitas yang paling kecil sekalipun, yakni keluarga. Oden mengatakan, "At times it seems there is no class of people not included within the scope of hospitality. Perhaps that is as it should be, for there are many ways to construe otherness, in terms of health, economic class, family relations, nationality, age, social status." 32 Jemaat mula-mula, yang berawal dari 120 orang, memberi ruang bagi orang yang baru bergabung, dengan segala perbedaan dan status asing yang ada.

\footnotetext{
32 Oden, And You Welcomed Me: A Sourcebook on Hospitality in Early Christianity, 10.

${ }^{33}$ Beberapa pemikiran yang mengaitkan pemahaman Trinitias dengan sikap gereja yang membuka diri terhadap yang lain dapat dilihat dalam: Miroslav Volf, After Our Likeness: The Church as the Image of the Trinity (Michigan: Eerdmans, 1998); John D. Zizioulas, Communion and Otherness: Further Studies in Personhood and the Church (New York: T\&T Clark, 2009).
}

Apakah gereja secara utuh telah memberi ruang persahabatan atau keterbukaan bagi masyarakan dunia? Sepertinya hal tersebut masih dilakukan oleh sebagian denominasi yang memiliki penghayatan yang utuh terhadap Allah Trinitas dan implikasinya dalam kehidupan sosial. ${ }^{33}$ Ada gereja yang melakukan praktik hospitalitas dengan implikasi mencari aman, atau bahkan mencari dukungan sosial, hingga mencari jiwa. ${ }^{34}$ Gereja-gereja dalam aliran Pentakosta dan Karismatik cenderung memiliki sikap yang eksklusif, sementara hospitalitas menuntut kemampuan membuka ruang komunikasi dan relasi dalam keragaman identitas. Adiprasetya menekankan pentingnya menjalin relasi dan partisipasi sebagai cara gereja membangun mezbah bagi pelayanan social liturgy, di samping ecclesial liturgy. ${ }^{35}$ Dialog dalam ruang keberagaman dapat digunakan sebagai cara bermisi ${ }^{36}$, tanpa harus menargetkan orang lain menjadi anggota gereja, karena pertobatan sejatinya merupakan pekerjaan Roh Kudus. Gereja-gereja Pentakostal sebaiknya mulai merancang program-progam yang terbuka dalam

34 Joon-Sik Park, "Hospitality as Context for Evangelism," Missiology: An International Review 30, no. 3 (2002): 385-395.

35 Joas Adiprasetya, "The Liturgy of the InBetween," Scottish Journal of Theology 72, no. 1 (2019): 64-81.

36 Fransiskus Irwan Widjaja and Harls Evan R. Siahaan, "Misi Dalam Dialog Iman Pada Ruang Virtual: Sebuah Model Reflektif Yohanes 3:1-21," THRONOS: Jurnal Teologi Kristen 2, no. 1 (2020): 40-48. 
ruang kebersamaan, tanpa harus curiga akan menjadi profan.

Jean Jeffress mengusulkan pembacaan nas Kisah Para Rasul 2:41-47 sebagai hospitalitas radikal; being church. ${ }^{37}$ Baginya, menjadi gereja berarti harus mampu berhospitalitas. Hal ini setidaknya mencerminkan bagaimana Allah, di dalam Yesus Kristus, telah begitu hospitable, menjadi hospitalitas terhadap orang-orang berdosa. Dosa membuat manusia menjadi asing di hadapan Allah; anugerah Kristus membuka ruang penerimaan bagi yang asing tersebut, bahkan menyebutnya sebagai sahabat (bdk. Yoh. 15:15). Alih-alih menghindari layaknya sebuah opsi ${ }^{38}$, hospitalitas harus diartikulasikan sebagai sebuah hakikat hidup menggereja, sebagaimana yang dilakukan oleh jemaat mula-mula. Walaupun, di masa lalu, praktik sosial gereja tidak jarang dikaitkan dengan stigma kristenisasi, namun prakatik hospitalitas harus terus dibangun secara natural; karena hospitalitas haruslah bersifat tanpa syarat ${ }^{39}$, untuk mencapai tujuan yang tidak berorientasi pada ekspansi atau kolonialisasi, melainkan partisipasi gereja pada ruang publik.

37 Jean Jeffress, "Radical Hospitality and Table Fellowship in a Time of Unwelcome: Being Church," Review \& Expositor 114, no. 3 (2017): 466-472.

${ }^{38}$ Pohl, Making Room: Recovering Hospitality as a Christian Tradition; Christine D Pohl, "Hospitality from the Edge: The Significance of Marginality in the Practice of Welcome," The Annual of the Society of Christian Ethics 15 (1995): 121-136.

\section{Gereja dan Tanggung Jawab Politik: Membangun Ruang Partisipasi}

Tanggung jawab politik merupakan tanggung jawab seluruh warga yang berada di sebuah wilayah negara tertentu. Tanggung jawab itu berkaitan dengan hak dan kewajiban; setiap orang atau warga negara memiliki hak dan kewajiban secara politis dalam konteks negaranya masing-masing. Jika hal ini dikaitkan dengan gereja, maka pertanyaannya adalah apakah gereja memiliki tanggung jawab atau kewajiban yang bersifat politik. Secara sederhana gereja sebagai bagian dari sebuah negara (warga) tentu memiliki tanggung jawab, termasuk secara politik. Tidak jarang tanggung jawab politik ini dimaknai secara profan, sehingga ada slogan: Gereja tidak boleh berpolitik secara praktis! Yohanes Susanta menganggap bahwa politik dapat digunakan sebagai alat untuk memperjuangkan kasih dan keadilan kepada sesama. ${ }^{40}$ Alih-alih menempatkannya pada stigma politik praktis, partispasi politik umat dapat mengikuti apa yang disarankan oleh Susanta, yaitu sebagai cara berbuat kasih dan keadilan pada sesama.

\footnotetext{
${ }^{39}$ Shepherd, The Gift of the Other: Levinas, Derrida, and a Theology of Hospitality.

${ }^{40}$ Yohanes Krismantyo Susanta, "Orang Kristen Dan Politik: Belajar Dari Kasus Salomo Dan Adonia Dalam Persaingan Menuju Takhta," DUNAMIS: Jurnal Teologi dan Pendidikan Kristiani 4, no. 1 (2019): 22-36.
} 
Keterlibatan orang-orang Kristen dalam kancah politik memang harus diakui masih minim, lepas dari jumlah Kekristenan di Indonesia yang memang sedikit, dan sering distigmatisasi dengan istilah minoritas. Namun demikian, keterwakilan umat Kristen di partai politik aras nasional belum memberikan tempat yang signifikan. Hal ini seharusnya dapat menjadi sebuah perenungan terlepas dari persoalan keterwakilan antara mayoritas dan minoritas. Hal yang tidak dapat dipungkiri adalah, ketika seseorang dapat menunjukkan nilai dan kualitas yang di atas rata-rata, memiliki karakter yang diidamkan oleh banyak orang, maka stigma tentang minoritas-mayoritas akan sedikit terurai dan dikesampingkan. Hal ini dapat dilihat dari fenomena yang terjadi pada diri seorang Ahok di kancah politik Jakarta beberapa tahun silam. Lepas dari jejak kontroversialnya, karakteristik politikus seperti Ahok telah mendapatkan porsi tersendiri dalam asa masyarakat Jakarta; itu sebabnya perlu sebuah konsolidasi politik yang transaksional untuk mengalahkannya.

Ahok memang bukanlah segala-galanya; ia pun akhirnya memiliki catatan kelam tentang kehidupan keluarganya, yang bagi sebagian orang dianggap sebagai "kegagalan.” Namun, jika mencermati dan me-

\footnotetext{
${ }^{41}$ Rosalia Kurni Setyawati, "Fenomena Ahok Dan Etos Kerja," in MAJALAH TARAKANITA FORUM, vol. 1, 2016, 31-34. Band. Theresia Intan, "Lunturnya Diskriminasi Dalam Meida: Citra Ahok Dalam Pemberitaan Media" (n.d.).
}

ngakui secara jujur, maka ada karakteristik yang diidamkan oleh banyak masyarakat Jakarta, lepas dari identitas suku dan agamanya, yakni tentang etos kerja. ${ }^{41}$ Dalam beberapa waktu, karakteristik terkait etos kerja sang politisi Kristen ini pun difigurkan oleh banyak orang, bahkan di luar Kekristenan sekalipun. Tidak sedikit gereja membuatnya menjadi sosok yang dapat dijadikan patron dalam lingkup dunia politik, terutama bagi politisi Kristen. Hal ini tidak dapat dipandang sebelah mata, bahwa Kekristenan sangat mungkin menempati ruang politik, berpartisipasi secara aktif dalam domain yang kerap terbungkus oleh stigma minoritas-mayoritas, hingga perilaku politik transaksional.

\section{Refleksi secara Pentakostal}

Refleksi teologi Pentakosta mengenai keterlibatan politik memang tidaklah dapat digeneralisir kepada seluruh gerejagereja Pentakostal, bahkan Karismatik, karena tentunya tidak semua merasa perlu untuk menafsirkan nas yang dianggap ciri khas Pentakostalisme dalam konteks keterlibatan politik. Harls Evan Siahaan menggagas tentang maksud politis Lukas dalam kajian Pentakostal berdasarkan nas Kisah Para Rasul 1:6-8. ${ }^{42}$ Permintaan para murid

42 Harls Evan R. Siahaan, "Memaknai Pentakostalisme Dalam Maksud Politis Lukas: Analisis Kisah Para Rasul 1:6-8," DUNAMIS: Jurnal Teologi dan Pendidikan Kristiani 3, no. 1 
agar Yesus melakukan restorasi (KJV, NIV, NAS) bagi Israel seolah memberi kesan dan pesan politis, bahwa harapan Israel masih menjadi locus berteologi para murid. Demikian halnya dengan penekanan istilah " $\mathrm{Ke}$ rajaan bagi Israel," yang memberi kesan politis pada permintaan itu. ${ }^{43}$ Mungkin saja, hal ini yang dimaksudkan Christina Petterson membingkai pembacaan Kisah Para Rasul dengan tema imperialisme ideologi. ${ }^{44}$ Tentunya, misi penyebaran Injil hingga ke ujung bumi tidak dapat dilepaskan dari diksi imperialis dalam tatanan ideologi agama.

Kelahiran gereja pada hari Pentakosta tidak semata-mata hadir sebagai sebuah entitas rohani, namun juga secara bersamaan sebagai wujud komunitas sosial yang baru. Amos Yong menyebut gereja sebagai "a political body," 45 dengan cara hidup yang dibedakan dari kelompok lain yang telah ada sebelumnya dalam dunia politik Romawi abad pertama. Peristiwa pencurahan Roh Kudus yang diikuti dengan manifestasi bahasa roh (Kis. 2:4) mengeks-

(2018): 52-73, https://sttintheos.ac.id/e-journal/ index.php/dunamis/article/view/174/140.

43 Jason Maston, "How Wrong Were the Disciples about the Kingdom? Thoughts on Acts 1:6," The Expository Times 126, no. 4 (January 14, 2015): 169-178, http://journals.sagepub.com/doi/10.1177/ 0014524614534567.

${ }^{44}$ Christina Petterson, Acts of Empire: The Acts of the Apostles and Imperial Ideology (Oregon: Wipf and Stock Publishers, 2020). Bdk. David Rhoads, David Esterline, and Jae Won Lee, Luke-Acts and Empire: Essays in Honor of Robert L. Brawley (Oregon: Wipf and Stock Publishers, 2011). presikan sebuah bahasa yang mewakili berbagai bangsa, yang sedang berkumpul di Yerusalem saat itu. Bahasa ini tidak harus dimaknai secara rohani belaka ${ }^{46}$, seperti halnya sebuah karunia yang disebut dalam 1 Korintus 12:10-11, karena Lukas menampilkan sebuah kontinuitas peristiwa yang dimulai dari janji yang diungkapkan Yesus pada Kisah Para Rasul 1:8, yang secara utuh merupakan bagian dari dialog Kisah Para Rasul 1:6-8. Yesus dianggap mampu mengatasi kekuatan penjajahan yang sedang dihadapi oleh bangsa Yahudi, karena peristiwa kebangkitan-Nya memberikan kesan superioritas; kebangkitan adalah kemenangan atas kematian. ${ }^{47}$ Alhasil, permintaan restorasi nasional dari 120 orang tersebut menyuarakan pengharapan politis dari sebuah bangsa yang terjajah.

Kuasa (kekuasaan) dapat menjadi potensi yang sangat besar dalam sebuah perubahan politis. Setelah Yesus bangkit dari kematian, Ia dianggap mampu melakukan perubahan karena kuasa-Nya yang mengatasi kematian (bdk. Mat 28:18) ${ }^{48}$, sehingga

\footnotetext{
${ }^{45}$ Amos Yong, In the Days of Caesar: Pentecostalism and Political Theology (Michigan: Eerdmans, 2010).

${ }^{46}$ Bdk. Harls Evan R Siahaan, "Bahasa Roh Dan Spiritualitas Perikoresis Dalam Peristiwa Pentakosta: Analisis Reinterpretatif Kisah Para Rasul 2: 1-13," LOGIA: Jurnal Teologi Pentakosta 2, no. 2 (2021): 18-31.

${ }^{47}$ Charles H. Talbert, "The Place Ofthe Resurrection in the Theology of Luke," Interpretation 46, no. 1 (1992): 19-30, int.sagepub.com.

${ }^{48}$ Ian K Duffield and Urban Theology Unit, "Difficult Texts : Matthew 28. 19-20," Theology
} 
memotivasi para murid mengekspresikan pengharapan mereka dengan meminta pemulihan bagi bangsa Israel. Kuasa sebagai potensi perubahan inilah yang dipertegas Lukas; yang akan diterima para murid, dan menjadi kekuatan yang mampu melakukan perubahan (transformasi). Kekuatan (kuasa) transformatif inilah yang merupakan potensi dinamika, yang berakar pada penggunaan kata "dunamis" (Kis. 1:8). Identitas Pentakostalisme menjadi semakin jelas di sini, di mana penggunaan kata kunci

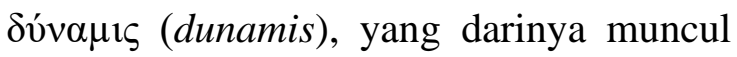
kata dinamis dan dinamika, menjadi potensi personal bagi para murid untuk melakukan perubahan, termasuk secara politis.

Apa yang disampaikan Lukas sangatlah jelas, bahwa pada hakikatnya perubahan politis akan menuntut adanya perubahan individual (dinamis). Starting point-nya adalah dunamis, sebagai potensi perubahan personal, yang mengimplikasikan perubahan politis. Setidaknya itulah titik awal untuk terjadinya pemulihan dalam skala yang lebih besar, pada ranah politik dan nasionalisme. Dinamika itu dikerjakan oleh Roh Kudus; Roh Kuduslah menjadi Penyebab perubahan, atau Dinamisator dalam sebuah perubahan politik atau kebangsaan. Artinya, Roh Kudus tidak hanya memperhati-

120, no. 2 (2017): 108-111, journals.sagepub.com/ home/tjx.

${ }^{49}$ Brian Howell, "Practical Belief and the Localization of Christianity: Pentecostal and kan kehidupan dalam gereja, melainkan tatanan yang lebih luas, bahkan profan, yakni dunia politik dan tatanan kehidupan berbangsa. ${ }^{49}$ Dinamika menjadi kunci dan potensi perubahan personal yang mengarah pada perubahan skala yang lebih besar. Ide teologi politik Lukas tidak dibangun pada intrik kekuasaan, melainkan untuk mendinamisir personalitas para murid agar menjadi dinamisator pada tatanan kehidupan mereka.

\section{Partisipasi Sosial Kaum Pentakostal}

Partisipasi sosial orang Kirsten tidak sekadar ditunjukkan dengan kemampuan berbuat baik kepada sesama dalam lingkup masyarakat luar gereja, namun juga hadir dalam setiap situasi sosial yang ada. Sikap peduli sosial dapat dibangun melalui perenungan biblikal, bahwa Allah menghendaki orang percaya hadir di tengah masyarakat, di mana gereja berada, dan melakukan segala sesuatu yang menunjukkan kasih Allah. Selain itu, sikap peduli juga dapat dikembangkan melalui praksis dalam gereja, memerhatikan sesama anggota gereja, hingga terlibat dalam menanggulangi persoalan yang dihadapi. Namun, tidak dipungkiri ada saja fenomena yang memperlihatkan di mana seseorang dapat peduli ter-

Denominational Christianity in Global/Local Perspective," Religion 33, no. 3 (July 2003): 233248, http://www.tandfonline.com/doi/abs/10.1016/ S0048-721X(03)00058-7. 
hadap kehidupan di luar gereja, sementara dirinya kurang aktif terlibat dalam kegiatan gerejawi. Membangun partisipasi sosial kaum Pentakostal berarti menstimulasi atau memotivasi jemaat untuk hadir dalam ruang publik melalui perenungan yang mewakili sikap teologis kaum Pentakostal.

Perenungan Pentakostal dimulai dari penghayatan peristiwa Pentakosta, hingga meneladani pola hidup jemaat mula-mula serta pelayanan para rasul. Soesilo menekankan kepedulian sosial kaum Pentakostal melalui perenungan (refleksi) sikap sosial jemaat mula-mula melalaui narasi Kisah Para Rasul 2:41-47. ${ }^{50}$ Penggunaan patron kehidupan jemaat mula-mula selalu dilakukan mengingat Kisah Para Rasul menjadi fokus teologisasi Pentakostalisme. Partisipasi sosial jemaat mula-mula belum terlihat jelas secara literal pada perikop tersebut, kecuali sikap peduli atau kesetiakawanan antarumat dalam meringankan penderitaan sesama. Narasi perikop hanya memperlihatkan kegiatan di dalam komunitas gereja, kecuali pada satu bagian akhir, ayat 47 , yang dapat dijadikan indikasi, pada klausa "mereka disukai semua orang." Kata laos yang digunakan dalam teks tersebut memberikan kesan, bahwa semua orang yang dimaksud

\footnotetext{
50 Soesilo, "Pentakostalisme Dan Aksi Sosial: Analisis Struktural Kisah Para Rasul 2 : 41-47."

${ }^{51}$ T. David Andersen, "The Meaning of EXONTE $\Sigma$ ХАРІN ПРО $\Sigma$ in Acts 2.47," New Testament Studies 34, no. 4 (1988): 604-610.
}

tidak hanya sebatas kelompok orang percaya, melainkan lebih pada kelompok-kelompok sosial-budaya.

Indikator keterlibatan sosial melalui narasi Kisah Para Rasul 2:41-47 memang tidak dapat dipastikan, kecuali keterlibatan dalam meringankan beban di antara anggota jemaat mula-mula. Klausa pada ayat 47 di atas dapat dipahami dalam dua hal. Pertama, bahwa semua orang menyukai pola kehidupan yang ditunjukkan jemaat mula-mula; kedua, bahwa semua orang pernah merasakan sikap terpuji mereka. Kuncinya pada kata yang digunakan, di mana ada perbedaan penekanan antara versi KJV (having favour) dan NIV (enjoying favour). T. David Andersen mengartikulasikan klausa tersebut sebagai bentuk perlakuan jemaat mula-mula terhadap semua orang (ton laon $)^{51}$, sementara Noble lebih menegaskannya sebagai sesuatu yang diperoleh oleh jemaat mula-mula bersama semua orang. ${ }^{52}$ Lepas dari objek favour yang ditekankan, faktanya ada pengakuan secara umum terhadap perilaku jemaat mula-mula. Lukas menonjolkan sikap kepedulian, solidaritas, dan kesetiakawanan, sebagai modal dalam rangka membangun kehidupan bersama. Setidaknya ini yang sedang dibangun, se-

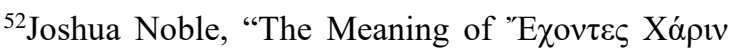
Прó $\varsigma$ in Acts 2.47: Resolving Some Recent Confusion," New Testament Studies 64, no. 4 (2018): 573-579.
} 
macam menstimulasi nilai-nilai tersebut dalam kebersamaan, yang tentunya menjadi hal yang dibutuhkan secara prinsip pada tatanan yang lebih luas, kehidupan di luar gereja.

Keterlibatan atau partisipasi gereja dalam ruang publik akan terasa hambar ketika kehadirannya dalam bentuk pasif, hanya sekadar ada secara formalitas, memenuhi ruang-ruang perjumpaan formal. Kehadiran gereja sebaiknya bersifat natural, menyapa sosial luar gereja tanpa ada tendensi apa pun kecuali hanya membangun persahabatan. ${ }^{53}$ Kontribusi kaum Pentakostal, dengan atribusi pelayanan kuasanya, akan sangat bermakna dalam lingkungan masyarakat yang membutuhkan jalan keluar masalah secara supranatural, tanpa harus memaksakan mereka menjadi anggota gereja. Kehadiran orang-orang yang penuh dengan kuasa dan hikmat Allah sebaiknya juga mampu mengeliminir persoalan yang dihadapi masyarakat secara umum. Apakah karunia ilahi hanya dikhususkan bagi umat dalam gereja saja; bukankah Yesus juga menyapa dan memberikan pertolongan kepada mereka yang membutuhkan, tanpa harus membeberkan persyaratan yang kental

\footnotetext{
53 Joas Adiprasetya and Nindyo Sasongko, "A Compassionate Space-Making: Toward a Trinitarian Theology of Friendship," Ecumenical Review 71, no. 1-2 (2019): 21-31.

54 Nickolas A Fox, The Hermeneutics of Social Identity in Luke-Acts (Wipf and Stock Publishers, 2021).
}

dengan rumusan agama? Sepertinya, harus ada gap yang tegas antara iman dan agama; antara beriman dan beragama.

Nickolas A. Fox menyarankan sebuah bingkai hermeneutik Lukas dan Kisah Para Rasul dengan identitas sosial. ${ }^{54} \mathrm{Hal}$ ini bukan tanpa alasan, karena Kisah Para Rasul menghadirkan berbagai kelompok sosial dengan identitasnya masing-masing, baik budaya, strata ekonomi, pendidikan, hingga agama. Kehadiran gereja mula-mula yang bersifat desentralisasi agama, dan memasuki ruang sosial yang lebih luas di sepanjang Kisah Para Rasul, memperlihatkan sebuah gerak dinamis (dunamis) menyapa kehidupan "asing" di luar gereja. Sikap hospitalitas, atau menyapa yang asing di luar gereja, merupakan cara untuk merevitalisasi kesaksian Kristen di tengah pluralitas sosial dan agama. ${ }^{55}$ Sementara, Adiprasetya menyebutnya sebagai cara membangun mezbah liturgi di luar gereja ${ }^{56}$; yang melaluinya umat dapat menyapa kehidupan luar gereja sebagai altar perjumpaan dengan yang Ilahi. Bahkan, Lorencin menegaskan bahwa hospitalitas merupakan relasi ritual yang memiliki kekuatan transformatif. ${ }^{57}$ Artinya, kehadiran dan partisipasi gereja pada ruang pu-

\footnotetext{
55 Yong, "The Spirit of Hospitality: Pentecostal Perspectives toward a Performative Theology of Interreligious Encounter."

56 Adiprasetya, "The Liturgy of the In-Between."

${ }^{57}$ Igor Lorencin, "Hospitality as a Ritual LiminalStage Relationship with Transformative Power: Social Dynamics of Hospitality and Patronage in the Third Epistle of John," Biblical Theology Bulletin 49 , no. 3 (2019): 146-155.
} 
blik tidak semata-mata berbicara tentang pemenangan jiwa atau penginjilan, melainkan memberikan kontribusi transformatif pada kehidupan sosial luar gereja.

Kebaikan Kristen dalam bentuk aksi dan kepedulian sosial memang harus terus dinyatakan dalam kerangka hidup bersama dengan "sesama." Perenungan teologis yang sarat dengan nilai iman Kristen tentang kasih (agape) setidaknya dapat dipahami dalam konteks kisah "orang Samaria yang baik hati" dalam Lukas 10:25-37. Perenungan itu dipercakapkan kepada para murid, demi memperoleh perspektif mereka tentang siapa yang seharusnya menjadi obyek kasih dalam iman Kristen. Kisah tersebut menampilkan toko-tokoh yang mewakili kelompok masyarakat, seperti Lewi dan para imam yang mewakili kaum rohaniawan. Pada akhirnya sosok rohaniawan tidak memberikan jaminan akan nilai kebaikan dan kepedulian sosial pada karakterisitik yang digambarkan melalui diri mereka. Yesus membangun sebuah konsep "sesama" bukanlah dibungkus oleh kesamaan label tertentu, seperti budaya, selera, agama, hingga pendidikan, karena pada akhirnya nilai-nilai teologi yang praksis banyak ditemukan pada sosok yang tidak terpikirkan sebelumnya.

\footnotetext{
58 Siahaan, "Karakteristik Pentakostalisme Menurut Kisah Para Rasul."

${ }^{59}$ Nancy Tatom Ammerman, Sacred Stories, Spiritual Tribes: Finding Religion in Everyday Life (Oxford: Oxford University Press, 2014).
}

Kepedulian sosial yang dibangun dalam kerangka hidup kebersamaan, tanpa memandang perbedaan merupakan ekspresi dari perenungan Pentakostal pada nas Kisah Para Rasul 2:47. Nas tersebut merupakan penutup dari sebuah perikop yang dapat diperlihatkan sebagai ciri atau karakteristik Pentakostalisme. ${ }^{58}$ Kuncinya adalah membangun kebersamaan dalam keragaman sebagai partisipasi kaum Pentakostal dalam ruang publik, yang menghadirkan "gereja" di tengah dunia. Pemikiran ini seperti apa yang dibagikan oleh Nancy Tatom Ammerman, tentang bagaimana menjadi seorang yang rohani dengan tetap berinteraksi dengan dunia ${ }^{59}$, atau berada di ruang sekular tanpa harus menjadi sekularis. ${ }^{60}$ Aksi sosial tidak harus menghilangkan identitas iman Kristen, dan mempertaruhkannya demi memperoleh jiwa yang diselamatkan. Partisipasi sosial, sekali lagi, bukanlah perangkat untuk menarik seseorang masuk ke dalam komunitasi, atau bahkan hingga ke gereja. Langkah iman yang membawa seseorang masuk ke gereja hanyalah karena perbuatan Roh Kudus dalam diri seseorang melalui kehadiran gereja di tengah lingkungan sosial.

\footnotetext{
${ }^{60}$ Harvey Cox, The Secular City: Secularization and Urbanization in Theological Perspective (New Jersey: Princeton University Press, 2013).
} 


\section{KESIMPULAN}

Gereja mula-mula memberikan teladan dan perenungan teologis, khususnya dalam perspektif Pentakostal tentang hospitalitas, yakni menyapa yang asing di luar gereja sebagai instrumen spirtualitas membangun partisipasi gereja masa kini pada ruang publik. Hospitalitas Pentakostal tidak dikondisikan dalam kerangka misiologis, dengan orientasi pada penambahan jumlah anggota jemaat (kuantitatif), melainkan kehadiran gereja pada domain luar gereja sebagai mezbah perjumpaan Yang Ilahi menyapa manusia dalam ranah sosial secara luas. Akhirnya, gereja-gereja Pentakostal dapat meningkatkan partisipasi umat pada ruang publik melalui perenungan teologis sikap hospitalitas jemaat mula-mula. Kajian ini dapat dikembangkan lebih lanjut dalam bentuk penelitian partispatif atau empiris, untuk melihat sejauh mana pemahaman teologis mengenai hospitalitas dalam perspektif Pentakostal diejawantahkan pada kehidupan jemaat Pentakostal.

\section{UCAPAN TERIMA KASIH}

Terima kasih kepada Harls Evan R. Siahaan yang telah memberikan banyak masukan dan memperbaiki naskah awal, hingga mengembangkan tema awal dengan ide hospitalitasnya. Terima kasih juga kepada Octavianus Nathanael, yang telah membaca dan memberikan masukan pada naskah awal, dan memberikan catatan yang melengkapi pembahasan perilaku jemaat Pentakostal di era modern.

\section{DAFTAR PUSTAKA}

Adiprasetya, Joas. "Hospitalitas: Wajah Sosial Gereja Masa Kini." Situs Komunitas Jemaat GKI Pondok Indah. Last modified 2013. Accessed November 12, 2020. https://gkipi.org/ hospitalitas-wajah-sosial-gerejamasa-kini/.

. "The Liturgy of the In-Between." Scottish Journal of Theology 72, no. 1 (2019): 64-81.

Adiprasetya, Joas, and Nindyo Sasongko. "A Compassionate Space-Making: Toward a Trinitarian Theology of Friendship." Ecumenical Review 71, no. 1-2 (2019): 21-31.

Alfaqi, Mifdal Zusron. "Memahami Indonesia Melalui Prespektif Nasionalisme, Politik Identitas, Serta Solidaritas." Jurnal Pendidikan Pancasila dan Kewarganegaraan 28, no. 2 (2015).

Ammerman, Nancy Tatom. Sacred Stories, Spiritual Tribes: Finding Religion in Everyday Life. Oxford: Oxford University Press, 2014.

Andersen, T. David. "The Meaning of EXONTE $\Sigma$ XAPIN ПPO $\Sigma$ in Acts 2.47." New Testament Studies 34, no. 4 (1988): 604-610.

Aritonang, Jan S. "Sejarah Pertumbuhan Gerakan Pentakostal Di Indonesia." Gema Teologi 35, no. 1/2 (2011).

Cleary, Edward L. Power, Politics, and Pentecostals in Latin America. Routledge, 2018.

Cox, Harvey. The Secular City: Secularization and Urbanization in Theological Perspective. New Jersey: Princeton University Press, 2013. 
Duffield, Ian K, and Urban Theology Unit. "Difficult Texts: Matthew 28. 1920." Theology 120, no. 2 (2017): 108111. journals.sagepub.com/home/tjx.

Fox, Nickolas A. The Hermeneutics of Social Identity in Luke-Acts. Wipf and Stock Publishers, 2021.

Haight, Roger. "The Mission of the Church in the Theology of the Social Gospel." Theological Studies 49, no. 3 (1988): 477-497.

Howell, Brian. "Practical Belief and the Localization of Christianity: Pentecostal and Denominational Christianity in Global/Local Perspective." Religion 33, no. 3 (July 2003): 233-248. http://www. tandfonline.com/doi/abs/10.1016/S0 048-721X(03)00058-7.

Intan, Theresia. "Lunturnya Diskriminasi Dalam Meida: Citra Ahok Dalam Pemberitaan Media" (n.d.).

Ireland, Rowan. "Pentecostalism, Conversions, and Politics in Brazil." Religion 25, no. 2 (1995): 135-145.

Jeffress, Jean. "Radical Hospitality and Table Fellowship in a Time of Unwelcome: Being Church." Review \& Expositor 114, no. 3 (2017): 466472 .

Kantorowicz, Ernst H. The King's Two Bodies: A Study in Mediaeval Political Theology. New Jersey: Princeton University Press, 1957.

Karkkainen, Veli-Matti. A Constructive Christian Theology for The Pluralistic World. Michigan: William B. Eerdmans Publishing Company, 2017.

Kiblinger, Kristin Beise. "Hospitality and the Other: Pentecost, Christian Practices, and the Neighbor." Buddhist-Christian Studies 29, no. 1 (2009): 156-159.

Lorencin, Igor. "Hospitality as a Ritual
Liminal-Stage Relationship with Transformative Power: Social Dynamics of Hospitality and Patronage in the Third Epistle of John." Biblical Theology Bulletin 49, no. 3 (2019): 146-155.

Luker, Ralph E. The Social Gospel in Black and White: American Racial Reform, 1885-1912. Univ of North Carolina Press, 1998.

Marshall, Ruth. Political Spiritualities: The Pentecostal Revolution in Nigeria. University of Chicago Press, 2009.

Maston, Jason. "How Wrong Were the Disciples about the Kingdom? Thoughts on Acts 1:6." The Expository Times 126, no. 4 (January 14, 2015): 169-178. http://journals. sagepub.com/doi/10.1177/00145246 14534567.

McGrath, Alister E. The Future of Christianity. Massachusetts: Blackwell Publisher, 2002.

Menzies, Robert P. Teologi Pentakosta. Malang: Gandum Mas, 2015.

Nasrudin, Juhana, and Ahmad Ali Nurdin. "Politik Identitas Dan Representasi Politik (Studi Kasus Pada Pilkada DKI Periode 2018-2022)." Hanifiya: Jurnal Studi Agama-Agama 1, no. 1 (2019): 34-47.

Newman, Saul. Political Theology: A Critical Introduction. Cambridge: Polity Press, 2019.

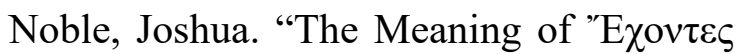
Xópıv Прós in Acts 2.47: Resolving Some Recent Confusion." New Testament Studies 64, no. 4 (2018): 573-579.

Oden, Amy G. And You Welcomed Me: A Sourcebook on Hospitality in Early Christianity. Nashville: Abingdon Press, 2001.

Park, Joon-Sik. "Hospitality as Context for Evangelism." Missiology: An 
International Review 30, no. 3 (2002): 385-395.

Petterson, Christina. Acts of Empire: The Acts of the Apostles and Imperial Ideology. Oregon: Wipf and Stock Publishers, 2020.

Pohl, Chistine D. Making Room: Recovering Hospitality as a Christian Tradition. Grand Rapids: Wm. B. Eerdmans Publishing, 1999.

Pohl, Christine D. "Hospitality from the Edge: The Significance of Marginality in the Practice of Welcome." The Annual of the Society of Christian Ethics 15 (1995): 121136.

Pranoto, Minggus M. "Sisi Gelap Kepemimpinan PentakostalKarismatik." GEMA TEOLOGIKA: Jurnal Teologi Kontekstual dan Filsafat Keilahian 5, no. 2 (2020): 175-186.

Rauschenbusch, Walter. A Theology for the Social Gospel. Michigan: IVP Books, 2008.

Rhoads, David, David Esterline, and Jae Won Lee. Luke-Acts and Empire: Essays in Honor of Robert $L$. Brawley. Oregon: Wipf and Stock Publishers, 2011.

Russel, Letty M. Just Hospitality: God's Welcome in a World of Difference. Louisville: Westminster John Knox Press, 2009.

Schmitt, Carl. Political Theology: Four Chapters on the Concept of Sovereignty. Chicago: University of Chicago Press, n.d.

Setyawati, Rosalia Kurni. "Fenomena Ahok Dan Etos Kerja." In MAJALAH TARAKANITA FORUM, 1:31-34, 2016.

Shepherd, Andrew. The Gift of the Other: Levinas, Derrida, and a Theology of Hospitality. Cambridge: James
Clarke \& Co., 2014.

Siahaan, Harls Evan. "Karakteristik Pentakostalisme Menurut Kisah Para Rasul." Dunamis: Jurnal Teologi dan Pendidikan Kristiani 2, no. 1 (2017): 12-28.

Siahaan, Harls Evan R. "Memaknai Pentakostalisme Dalam Maksud Politis Lukas: Analisis Kisah Para Rasul 1:6-8." DUNAMIS: Jurnal Teologi dan Pendidikan Kristiani 3, no. 1 (2018): 52-73. https:// sttintheos.ac.id/e-journal/index.php/ dunamis/article/view/174/140.

Siahaan, Harls Evan R. "Bahasa Roh Dan Spiritualitas Perikoresis Dalam Peristiwa Pentakosta: Analisis Reinterpretatif Kisah Para Rasul 2: 113." LOGIA: Jurnal Teologi Pentakosta 2, no. 2 (2021): 18-31.

Siahaya, Johannis, and Harls Evan R Siahaan. "Menggagas Hospitalitas Pentakostal: Membaca Ulang Kisah Para Rasul 2: 44-47 Di Masa Pandemi." DUNAMIS: Jurnal Teologi dan Pendidikan Kristiani 5, no. 2 (2021): 426-439.

Soesilo, Yushak. "Pentakostalisme Dan Aksi Sosial: Analisis Struktural Kisah Para Rasul 2: 41-47." DUNAMIS: Jurnal Teologi dan Pendidikan Kristiani 2, no. 2 (2018): 136-151. http://sttintheos.ac.id/e-journal/index. php/dunamis/article/view/172/134.

Susanta, Yohanes Krismantyo. "Orang Kristen Dan Politik: Belajar Dari Kasus Salomo Dan Adonia Dalam Persaingan Menuju Takhta." DUNAMIS: Jurnal Teologi dan Pendidikan Kristiani 4, no. 1 (2019): 22-36.

Sutherland, Arthur. I Was a Stranger: A Christian Theology of Hospitality. Nashville: Abingdon Press, 2010.

Talbert, Charles H. "The Place Ofthe Resurrection in the Theology of 
Luke." Interpretation 46, no. 1 (1992): 19-30. int.sagepub.com.

Tambunan, Elia. "Pentakostalisme Dan Teori Sosial Kontemporer." Jurnal Teologi Amreta 2, no. 1 (2018).

Volf, Miroslav. After Our Likeness: The Church as the Image of the Trinity. Michigan: Eerdmans, 1998.

Vondey, Wolfgang. "The Impact of Culture and Social Justice on Christian Formation in Pentecostalism." Journal of Pentecostal Theology 24, no. 2 (2015): 201-216.

White, Ronald Cedric, Charles Howard Hopkins, and John Coleman Bennett. The Social Gospel: Religion and Reform in Changing America. Temple University Press, 1976.

Widjaja, Fransiskus Irwan, and Harls Evan R. Siahaan. "Misi Dalam Dialog Iman Pada Ruang Virtual: Sebuah Model Reflektif Yohanes 3:1-21." THRONOS: Jurnal Teologi Kristen 2, no. 1 (2020): 40-48.
Yong, Amos. Hospitality and The Other: Pentecost, Christian Practices, and the Neighbor. New York: Orbis Books, 2008.

- In the Days of Caesar: Pentecostalism and Political Theology. Michigan: Eerdmans, 2010.

- "The Spirit of Hospitality: Pentecostal Perspectives toward a Performative Theology of Interreligious Encounter." Missiology: An International Review 35, no. 1 (2007): 55-73.

Zaluchu, Sonny Eli. "Eksegesis Kisah Para Rasul 2:42-47 Untuk Merumuskan Ciri Kehidupan Rohani Jemaat MulaMula Di Yerusalem." EPIGRAPHE: Jurnal Teologi dan Pelayanan Kristiani 2, no. 2 (2019): 72-82.

Zizioulas, John D. Communion and Otherness: Further Studies in Personhood and the Church. New York: T\&T Clark, 2009. 